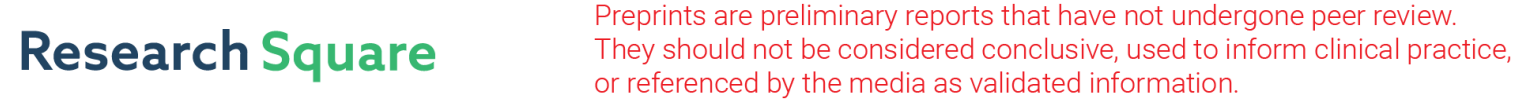 \\ Enhanced Frictional Properties of NiO-based Nanocomposites With the Addition of GDC
}

Jooho Park

Sungkyunkwan University College of Engineering https://orcid.org/0000-0002-9082-4892

\section{Minwoo Ahn}

Sungkyunkwan University College of Engineering

\section{Seungwoo Han}

Sungkyunkwan University College of Engineering

\section{Wonyoung Lee}

Sungkyunkwan University College of Engineering

YoungZe Lee ( $\sim$ yzlee@skku.edu )

Sungkyunkwan University College of Engineering

\section{Research Article}

Keywords: NiO-GDC metal matrix composite (NiO/GDC MMC), wear characteristics, worn surface morphologies, ball-on-disk (BoD) testing

Posted Date: April 13th, 2021

DOI: https://doi.org/10.21203/rs.3.rs-294947/v1

License: (c) (i) This work is licensed under a Creative Commons Attribution 4.0 International License.

Read Full License 


\title{
Enhanced Frictional Properties of NiO-based Nanocomposites with the Addition of GDC.
}

\author{
Jooho Park ${ }^{\text {a }}$, Minwoo Ahn ${ }^{\text {a }}$, Seungwoo Han ${ }^{\text {a, }}$, Wonyoung Lee *a and YoungZe Lee *a \\ ${ }^{*}$ Corresponding authors \\ ${ }^{a}$ Department of Mechanical Engineering, Sungkyunkwan University, South Korea. \\ leewy@skku.edu \\ yzlee@skku.edu
}

\begin{abstract}
The tribological performance and friction-induced vibration of Gd0.2-Ce0.8O1.9 (GDC) reinforced nickel oxide $(\mathrm{NiO})$ metal matrix composites prepared via sintering on the tribological performance, as well as friction induced vibration were investigated. Compared to pure $\mathrm{NiO}$, the composites exhibit improved mechanical properties, such as a relatively high dislocation density, hardness and small grain size. The results show that GDC-reinforced NiO nanocomposites feature improved tribological performance and can suppress the occurrence of friction-induced vibration under variable loading conditions. Furthermore, the generated acceleration can be suppressed by wear particles generated during the friction process, acting as the third body at the contact interface. As a result, the addition of GDC reduces the grain size of the composite, increases hardness, and improves tribological properties through the synergetic effect of the solid lubricating action of $\mathrm{NiO}$ and the role of the third body of the wear particle.
\end{abstract}

Keywords: NiO-GDC metal matrix composite (NiO/GDC MMC); wear characteristics; worn surface morphologies; ball-on-disk (BoD) testing

\section{Introduction}

Over the last few decades, metal matrix composite (MMC) coatings with attractive mechanical and physical properties, such as high strength, thermal stability, and specific modulus, have been reported [1]. Such MMCs combine the ductility and toughness of metallic materials with the strength and modulus of ceramic materials, resulting in enhanced shear strength compression and heat durability [2]. These coatings possess improved properties such as wear, corrosion, and oxidation resistances, and are also capable of self-lubrication; hence, they can protect substrates against severe environments during operation [3-5]. In particular, Ni-based MMCs are widely used as low-cost solid lubricants with good wear performance under hightemperature conditions [6-8]. For example, Ni-based composites are employed to enhance surface quality, such as cutting tools, rollers and plungers, turbine engine components, piston head and rods, and wearing plates [7-11].

Stott et al. described three growth conditions of oxides formed on the surface of substrate, such as $\mathrm{Ni}$ and $\mathrm{Co}$, and displayed the process through which the generated oxides developed into "glaze". It was concluded that the glaze layers consisted of fine crystalline oxide particles compacted or compressed into an oxide layer during sliding. In addition, the substrate was preoxidized at high temperatures to form an oxide on the surface. Sliding test was conducted to observe the formation of the glaze layer. However, the sliding test at room temperature (RT) showed a higher friction coefficient and wear rate than the experimental results at higher temperatures [12]. Hager et al. oxidized a Ni disk at high temperature $\left(1000{ }^{\circ} \mathrm{C}\right)$ to investigate 
the formation mechanism of the $\mathrm{NiO} / \mathrm{Ti} 6 \mathrm{Al} 4 \mathrm{~V}$ lubricating film at various temperatures, including room RT; they secured a nickel oxide layer on the surface and conducted a fretting wear test. $\mathrm{Ni}_{2} \mathrm{O}_{3}$ formed through heat treatment was reduced to $\mathrm{NiO}$ at a high temperature to form a glaze tribofilm, resulting in a decrease in the friction coefficient and wear rate. However, at RT, it still showed a relatively high coefficient of friction and wear rate, unlike the experiments at high temperatures [13]. It is well known that, during take-off (i.e., during the heating-up period) and running-in period, wear is most severe, producing many large wear particles not only in general metals [14, 15] but also in MMCs [16-18]. Therefore, it is necessary to develop an MMC with a low coefficient of friction and wear rate, even during the initial test period, including the take-off under RT conditions. To provide a smooth, solid lubricant for wear particles under experimental conditions, $\mathrm{NiO}$ powder was used to form a composite to suppress the generation of $\mathrm{Ni}_{2} \mathrm{O}_{3}$, which may occur during the experimental process when $\mathrm{Ni}$ is added to the composite.

This study aims to investigate the enhanced tribological properties of NiO-based nanocomposites with the addition of GDC. We provide a detailed description of the tribological properties and surface morphology of $\mathrm{NiO} / \mathrm{GDC}$ composites with varying GDC ratios during reciprocating frictional behavior at $\mathrm{RT}$, in order to achieve a better understanding of the friction and wear behavior against AISI52100 bearing steel. In addition, the evolution of the friction coefficient, wear rate, acceleration due to relative motion, grain size, hardness and fracture toughness were studied. Meanwhile, the correlation between acceleration, wear rate, and third -body wear was obtained. Lastly, the wear mechanism of the specimen in accordance with the added GDC ratio was discussed.

\section{Materials and experiments}

\subsection{Fabrication of NiO/GDC composites}

NiO (KOJUNDO CHEMICAL) features an FFC crystal structure [19], which provides good fracture toughness $[20,21]$, and it is used as a matrix material for MMCs because the glaze generated on the surface through friction can lower the friction coefficient and wear rate. Gd0.2-Ce0.8O1.9 (GDC) powder (Rhodia) was used as the reinforcement material because of its high hardness and low thermal conductivity [22]; it can be applied to the thermal barrier coating material of turbine engine components [23, 24]. Both powders were ball-milled together with different NiO:GDC mass ratios of 100:0, 97:3, 95:5, 90:10, 85:15, and 80:20 with ethanol for $72 \mathrm{~h}$, to achieve a uniform size distribution. After drying at $80{ }^{\circ} \mathrm{C}$ for $6 \mathrm{~h}, \mathrm{NiO}$ and GDC powders were pressed at $40 \mathrm{MPa}$ and sintered at $1400{ }^{\circ} \mathrm{C}$ for $5 \mathrm{~h}$ to form dense, disk-like $\mathrm{NiO} / \mathrm{GDC}$ pellets with a diameter of $10 \mathrm{~mm}$ and thickness of $\sim 1.1 \mathrm{~mm}$.

\subsection{Tribological testing}

Friction and wear tests were performed using a reciprocating ball-on-disk tribometer (AUTOTECH, Korea) under dry sliding conditions. All tests were carried out under laboratory conditions (temperature $\approx 25{ }^{\circ} \mathrm{C}$; relative humidity $\approx 50 \%$ ). The system allows the measurement of the friction coefficient and acceleration by using a load cell and accelerometer, 
respectively. The accelerometer measures the acceleration caused by the relative motion of the specimens. As sub-micron-sized hard-particle-reinforced $\mathrm{NiO}$ matrix composites are considered for use in applications such as cutting tools, turbine engine components, piston head and rods, and aerospace engineering, the wear test conditions were set to match those observed in such practical applications. Therefore, the tests were performed at a constant applied load of 40 and $50 \mathrm{~N}$ with a sliding speed of $20 \mathrm{~mm} / \mathrm{s}$ for 18000 cycles. An AISI 52100 steel ball (848 $\mathrm{HV}$, elastic modulus of $210 \mathrm{GPa}$ ) with a diameter of $10 \mathrm{~mm}$ was used as the counterpart. All contact surfaces of the specimens were treated with the same polishing process. The mean roughness $(\mathrm{Ra})$ of the $\mathrm{NiO} / \mathrm{GDC}$ composite used in the test was $0.39 \pm 0.02 \mu \mathrm{m}$. Four repeated tests were conducted for each set of frictional pairs. The wear rate of the composites after each test was calculated by measuring the wear width and depth using a surface profilometer (SJ410, Mitutoyo, resolution: $0.001 \mu \mathrm{m})$ and an optical microscope (BX51M, OLYMPUS, resolution: $0.35 \mu \mathrm{m})$.

\subsection{Microstructure observation of $\mathrm{NiO} / \mathrm{GDC}$ composites}

The grain size and crystal structure of the composite were evaluated using X-ray diffraction (XRD, Expert pro-MPD, PANalytical) with $\mathrm{Cu}-\mathrm{K} \alpha$ radiation $(0.15418 \mathrm{~nm})$, and the data were analyzed using PANalytical software. The morphologies of the composites were examined using the secondary electron image (SEI) mode and backscattered electron image (BEI) mode in field emission scanning electron microscopy (FE-SEM, JSM7000F, JEOL). Furthermore, surface topography information including surface roughness $(\mathrm{Ra})$, was obtained.

\section{Results and discussion}

\subsection{Characterization of $\mathrm{NiO} / \mathrm{GDC}$ composites}

Fig. 1 shows the XRD patterns for determining the crystalline phases of the matrix composites with different NiO:GDC mass ratios and sintered at $1400{ }^{\circ} \mathrm{C}$ for $5 \mathrm{~h}$. Hereinafter, the matrix composites with different NiO:GDC mass ratios are denoted as 100:0, 97:3, 95:5, 90:10, 85:15, and 80:20, respectively. The 100:0 composite represents the pure $\mathrm{NiO}$ ceramic, whereas the 97:3, 95:5, 90:10, 85:15, and 80:20 composites represent matrix composites containing both $\mathrm{NiO}$ and GDC phases with the corresponding mass ratios. In addition, the crystalline structures of the $\mathrm{NiO}$ and GDC phases were verified using an XRD fitting program. Inducing the formation of $\mathrm{NiO}$ by subjecting the $\mathrm{Ni}$-added composite to friction under high-temperature and high-speed conditions, or exposing the surface to high-temperature conditions can lead to the formation of $\mathrm{Ni}_{2} \mathrm{O}_{3}$ as well as $\mathrm{NiO}$. Therefore, in this study, $\mathrm{NiO}$ powder was used to form a composite to suppress the generation of $\mathrm{Ni}_{2} \mathrm{O}_{3}$, which can occur during the experimental process when $\mathrm{Ni}$ is added to the composite. As secondary phases such as $\mathrm{Gd}_{2} \mathrm{O}_{3}, \mathrm{Ni}_{2} \mathrm{O}_{3}$ and metal $\mathrm{Ni}$ do not exist, the possibility of applying the synthesis method used in this study to obtain $\mathrm{NiO} / \mathrm{GDC}$ composites is confirmed. The mass ratios of the fabricated matrix composites were calculated using XRD analysis; subsequently, the volume ratios were converted with the densities of $\mathrm{NiO}$ and GDC phases, i.e., 6.67 and $7.22 \mathrm{~g} / \mathrm{cm}^{3}$, respectively. As shown in Table 1, the calculated mass and volume fractions showed good agreement with the designed ratios, with an error range of $\pm 5 \%$. 


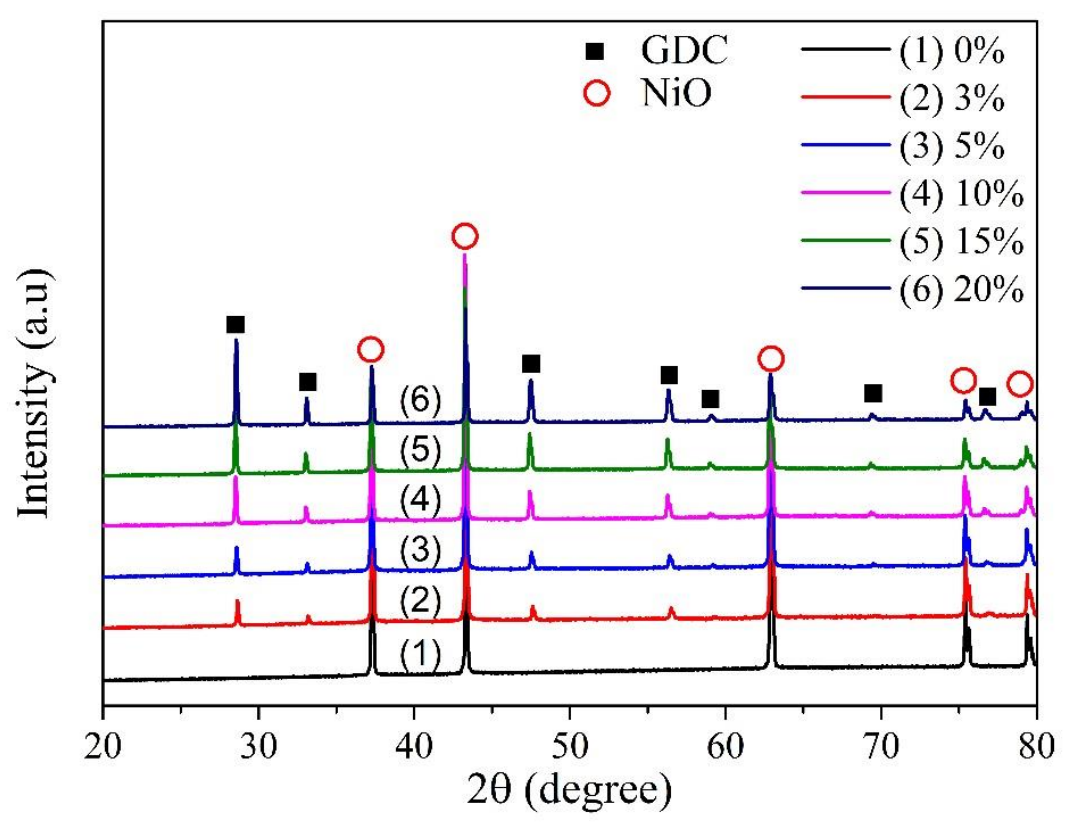

Fig. 1 XRD patterns of NiO/GDC composite

Table. 1 Calculation of material volume and mass fraction by XRD analysis

\begin{tabular}{ccccc}
\hline \multirow{2}{*}{ Samples } & \multicolumn{2}{c}{ Measure mass fraction $(\%)$} & \multicolumn{2}{c}{ Measured volume fraction $(\%)$} \\
\cline { 2 - 5 } & NiO & GDC & NiO & GDC \\
\hline $100: 0$ & 100 & 0 & 100 & 0 \\
$97: 3$ & 99.82 & 1.08 & 99 & 1 \\
$95: 3$ & 97.73 & 2.27 & 9.9 & 2.1 \\
$90: 10$ & 92.15 & 7.85 & 92.7 & 7.3 \\
$85: 15$ & 87.56 & 12.44 & 88.4 & 11.6 \\
$80: 20$ & 75.46 & 24.54 & 76.9 & 23.1 \\
\hline
\end{tabular}

Fig. 2 shows the SEM images of the fabricated matrix composites with different NiO:GDC mass ratios. SEM images of the same area, obtained under the SEI and BEI modes, were compared to investigate the detailed microstructures of the fabricated composites. In the SEI mode, secondary electrons are emitted significantly close to the specimen surface. In contrast, in the BEI mode, backscattered electrons are reflected via elastic scattering from a deeper region of the specimen. According to the atomic weight, the signal intensity or contrast observed in the BEI mode could be changed. Heavier atoms appear brighter than the lighter ones, because the former have a higher energy due to the backscattered electrons. As the GDC phase comprises Gd and Ce cations with atomic weights of 157.27 and 140.11, respectively, and the $\mathrm{NiO}$ phase comprises $\mathrm{Ni}$ and $\mathrm{O}$ cations with atomic weights of 58.69 and 15.99, respectively, the GDC phase appears brighter than the NiO phase in the BEI mode. As the 100:0 composite is a homogeneous material, no difference in contrast was observed. However, in the matrix composite, the GDC phase (bright regions) and $\mathrm{NiO}$ phase (dark regions) were clearly identified. Both the $\mathrm{NiO}$ and GDC phases were uniformly distributed along the entire length of the nanofibers. The proportion of bright GDC phases increased with increasing GDC content. In particular, the 85:15 nanofibers, as shown in Figs. 2(b-5), displayed the most uniform distribution of the $\mathrm{NiO}$ and GDC phases, as compared to the other mixing ratios. 

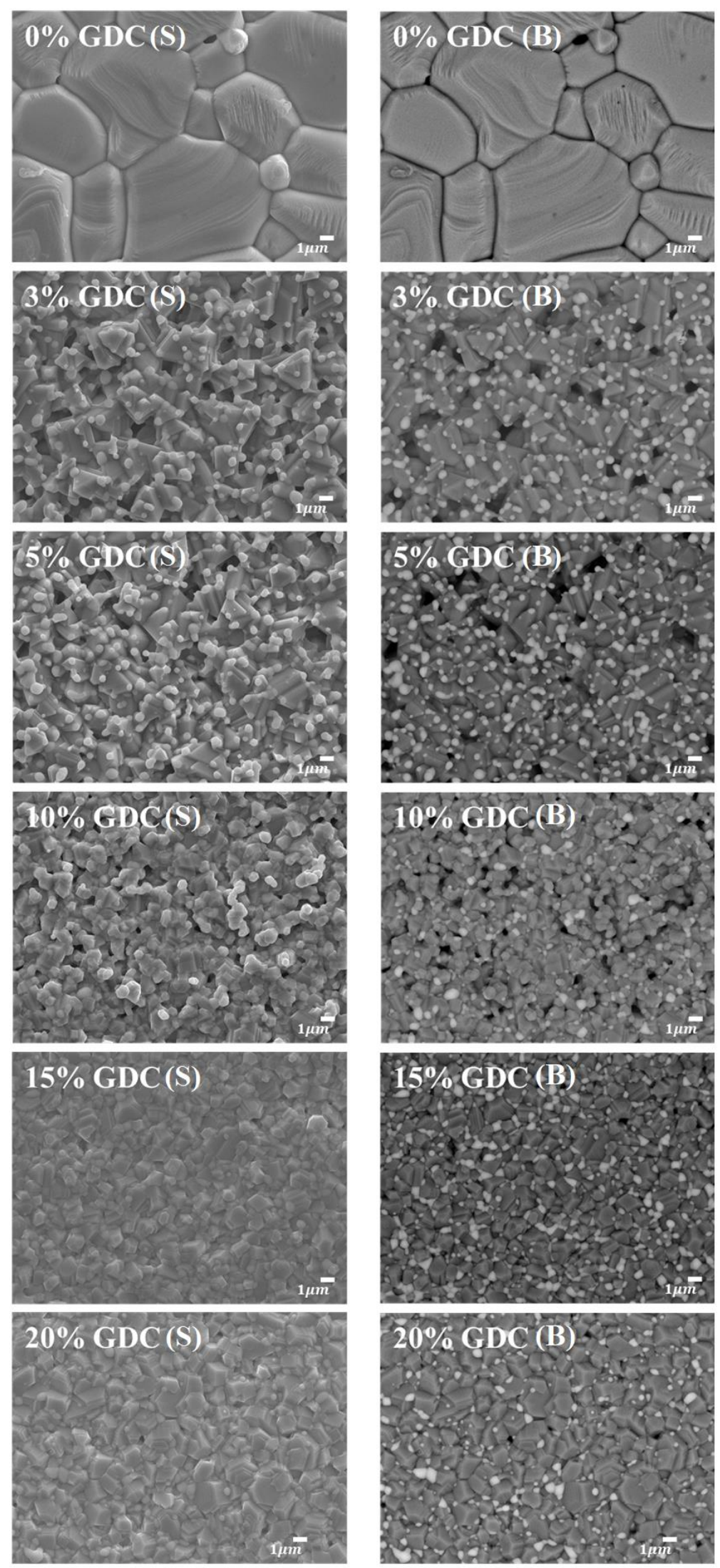

Fig. 2 SEM images of samples, S for SEI image (left) and B for BEI image (right). 
Fig. 3 shows the nanohardness and fracture toughness of the matrix composites with different NiO:GDC mass ratios. By using a nanoindenter (NanoTest Vantage Platform, MICRO MATERIALS), the nanohardness of each specimen was measured. These measurements of nanohardness were performed under a constant load of $500 \mathrm{mN}$, and the loading and unloading times were 20s, and 10s, respectively. Indenting was conducted five times and the average data of the results plotted, as shown in Fig. 3 (a). As the amount of GDC added increased, the hardness of the matrix composite also tended to increase. When the added GDC increased from 0 to $15 \%$, the hardness increased by $38.11 \%$, whereas when it increased from $0 \%$ to $20 \%$, the hardness increased by $41.22 \%$. However, it was shown that the increment in hardness decreased with the addition of $15 \%$ or more of GDC. Fig. 3 (b) shows the fracture toughness of the $\mathrm{NiO} / \mathrm{GDC}$ composites determined via the indentation method. To calculate the fracture toughness of matrix composites, Young's modulus is required. With the reduced modulus, $E_{r}$, of matrix composites, which can be measured by nanoindenting, Young's modulus can be calculated as follows [25]:

$$
\frac{1}{E_{r}}=\frac{\left(1-v^{2}\right)}{E}+\frac{\left(1-v_{i}^{2}\right)}{E_{i}}
$$

where E and $v$ are the Young's modulus and Poisson's ratio of the specimen, respectively, and $E_{i}$ and $v_{i}$ are the corresponding parameters for the indenter. The indentation fracture toughness was calculated using the equation proposed by Antis et al. [26]:

$$
K_{I C}=0.016\left(E / H_{v}\right)^{1 / 2}\left(P / a^{3 / 2}\right)
$$

The fracture toughness of the pure $\mathrm{NiO}$ matrix was $5.12 \pm 0.34 \mathrm{MPa} \cdot \mathrm{m}^{1 / 2}$, which agrees with the previously reported value $\left(5.2 \pm 0.8 \mathrm{Mpa} \cdot \mathrm{m}^{1 / 2}\right)$ evaluated via the VAMAS procedure on pre-notched specimens [27]. The fracture toughness of the composites decreased with increasing GDC contents, however, all these values were higher than that of $\operatorname{GDC}\left(1.27 \pm 0.13 \mathrm{Mpa} \cdot \mathrm{m}^{1 / 2}\right)[22]$. 
(a)
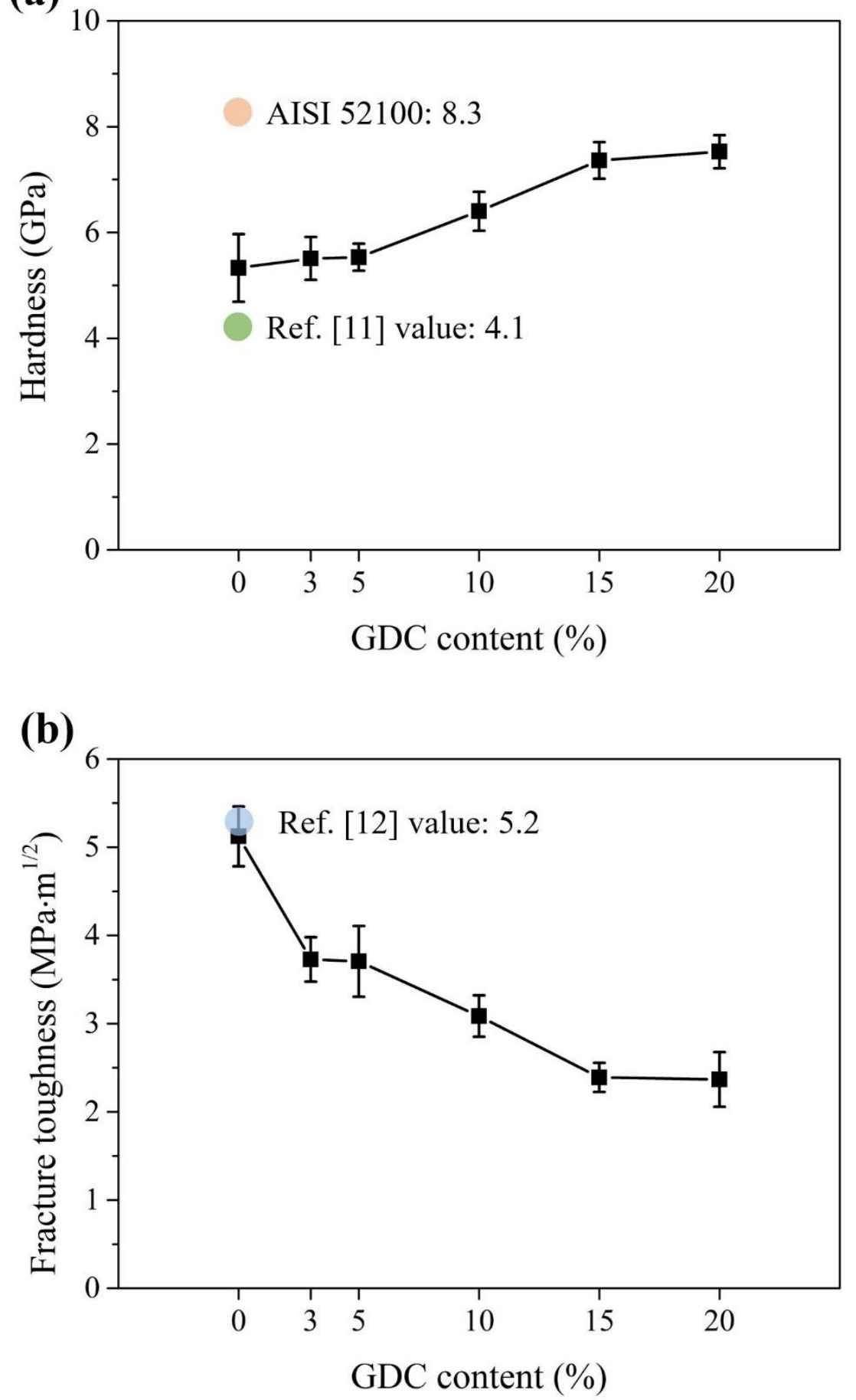

Fig. 3 Micro-hardness and fracture toughness of NiO/GDC composites according to the added GDC mass ratio (a) Micro-hardness (Vickers hardness, GPa), (b) Fracture-Toughness $\left(K_{I C}\right.$, $\left.M P a \cdot m^{1 / 2}\right)$. 
Fig. 4 presents the crystallite size and dislocation density of the NiO/GDC composites as a function of the GDC content. The average crystallite size obtained from the XRD patterns of the NiO/GDC composites was calculated according to Scherrer's equation [27]:

$$
D=\frac{0.9 \lambda}{B \times \cos \theta}
$$

where $\mathrm{D}$ is the crystallite size, $\lambda$ is the wavelength of the $\mathrm{X}$-ray $(0.154 \mathrm{~nm}), \mathrm{B}$ is the full width half maximum, and $\theta$ is the diffraction angle. As shown in Fig. 4 (a), the average grain size of the $\mathrm{NiO} / \mathrm{GDC}$ composites decreased by approximately $15.45 \%$ as the GDC content increased from 0 to $20 \%$. The observed decreasing trends of the average grain size the of $\mathrm{NiO} / \mathrm{GDC}$ composites can be explained by the different melting temperatures that thermodynamically affected grain growth [28, 29]. In the case of adding Gd with a low melting point (LMP; $\sim 1300^{\circ} \mathrm{C}$ ) to $\mathrm{YSZ}$ with a high melting point (HMP; $\sim 2600^{\circ} \mathrm{C}$ ) [28] and also, when adding $\mathrm{SnO}_{2}$ (HMP; $\sim 1630^{\circ} \mathrm{C}$ ) to $\alpha-\mathrm{Fe}_{2} \mathrm{O}_{3}\left(\mathrm{LMP} ; \sim 1530^{\circ} \mathrm{C}\right)$ [29], the grain growth of the matrix material was limited due to the reduced the grain boundary energy caused by the addition. In this study, by addition of GDC with a melting point approximately $2400{ }^{\circ} \mathrm{C}$ to $\mathrm{NiO}$ with a melting point approximately $1950{ }^{\circ} \mathrm{C}$, the grain boundary energy of the $\mathrm{NiO}$ phase could be lowered by the adjacent GDC phase, thereby suppressing grain growth in the former. The change in the dislocation density of the NiO/GDC composites increasing GDC content is shown in Fig. 4 (b). The dislocation density is calculated as follows [30]:

$$
D=K / \sqrt{\rho}
$$

where $D$ is the average grain size, $\mathrm{K}$ is a proportionality constant, and $\rho$ is the total dislocation density. Fine granularity is achieved through the formation of dislocation cells with the accumulation of misorientation across the dislocation cell boundaries [31]. As this occurs stochastically [32, 33], the higher the dislocation density, the faster the accumulation of misorientaion, resulting in an increase in the yield stress [34]. Therefore, an increase in dislocation density increases the number of fine grains in the composite, contributing to an increase in hardness (Fig. 3(a)) and a decrease in grain size (Fig. 4(a)). 
(a)

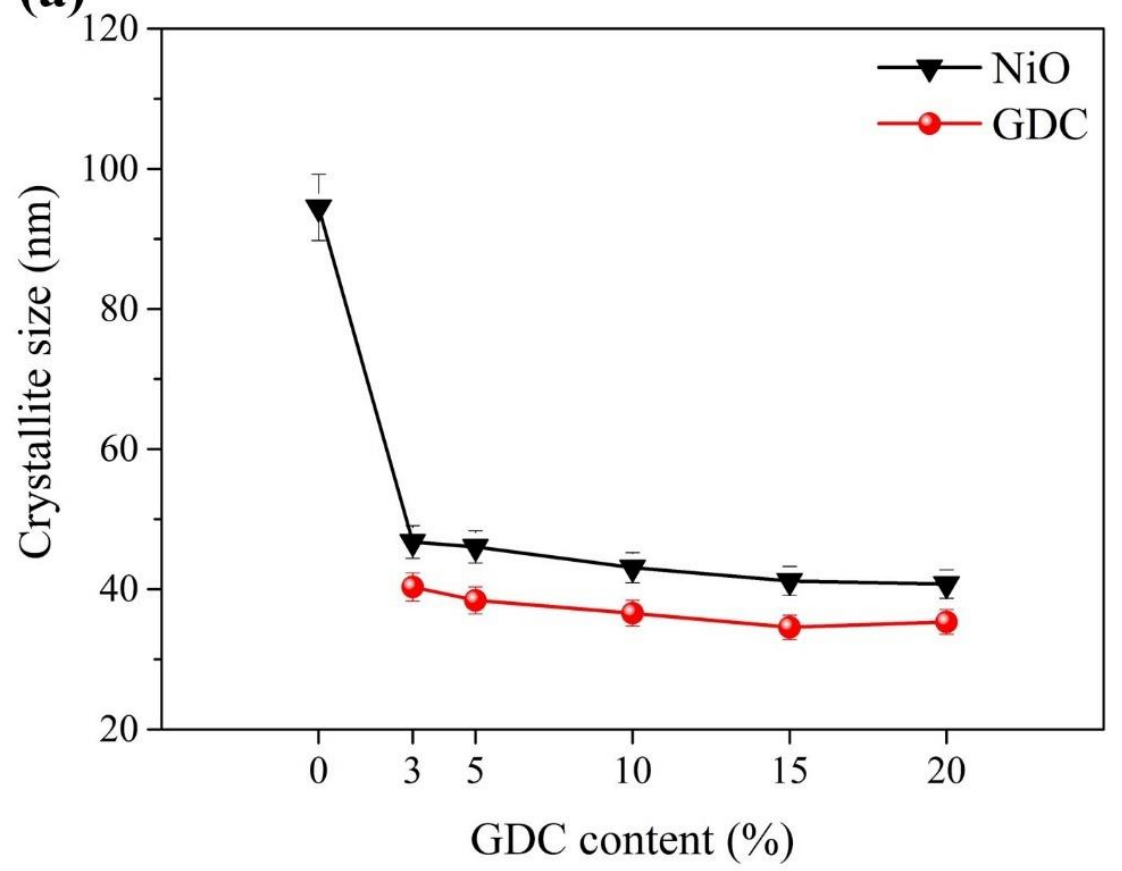

(b)

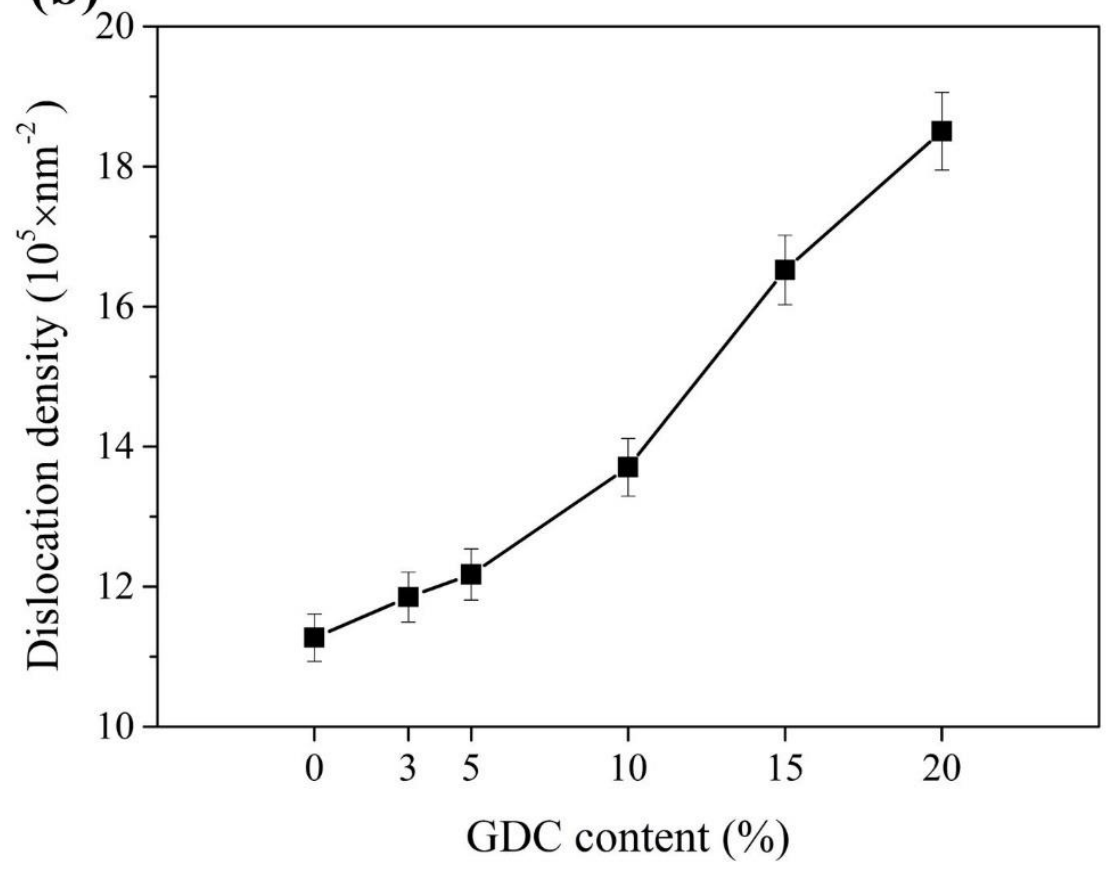

Fig. 4 Grain size and dislocation density of $\mathrm{NiO} / \mathrm{GDC}$ composites according to added GDC mass ratio (a) Crystallite size of composites $(\mathrm{nm})$, (b) Dislocation density $\left(10^{5} \times \mathrm{nm}^{-2}\right)$ 


\subsection{Tribological analysis of the $\mathrm{NiO} / \mathrm{GDC}$ composites}

Fig. 5 (a) shows the variations in the steady-state friction coefficient of the NiO/GDC composites as a function of the GDC content under the applied normal loads of 40 and $50 \mathrm{~N}$. Regardless of the amount of GDC in the composites, the friction coefficients under $40 \mathrm{~N}$ were lower than those under $50 \mathrm{~N}$. The friction coefficient of the composites under $40 \mathrm{~N}$ were in the range of 0.58 to 0.63 . The coefficient of friction for pure $\mathrm{NiO}$ was $0.63 \pm 0.05$. For the $\mathrm{NiO} / \mathrm{GDC}$ composites under $50 \mathrm{~N}$, the friction coefficients were in the range of 0.68 to 0.79 , and the coefficient of pure $\mathrm{NiO}$ was $0.73 \pm 0.04$. Fig. 5 (b) presents a comparison of the friction traces of the composites under a normal load of $50 \mathrm{~N}$ with respect to the number of cycles during the continuous reciprocating test (only three composites are shown for brevity). The composite with 15\% GDC showed a steady-state coefficient of friction with a slight fluctuation and a moderate increase. In the sample with $20 \%$ GDC, a different behavior was observed; the steady-state friction coefficient was reached quickly with large fluctuations in the range of 0.65 to 0.85 . The peak value of the acceleration caused by the stick-slip phenomenon during the sliding of the friction system is shown in Fig. 5 (c). In this experiment, under a constant load of $50 \mathrm{~N}$, the highest value of $6.73 \pm 0.65 \mathrm{~m} / \mathrm{s}^{2}$ was measured for the pure $\mathrm{NiO}$ sample, and the lowest value of $2.71 \pm 0.52 \mathrm{~m} / \mathrm{s}^{2}$ was measured for the sample to which $15 \%$ GDC was added. Fig. 5 (d) shows the average wear rate according to the amount of GDC added, as determined through the tribological test. The highest wear rate, i.e., $7.28 \pm 0.84\left(10^{-5} \mathrm{~mm}^{-5} / \mathrm{m}\right)$, was measured for the pure $\mathrm{NiO}$ sample in the experiment conducted under a load of $50 \mathrm{~N}$, and the lowest wear rate, i.e., $1.21 \pm 0.13\left(10^{-5} \mathrm{~mm}^{-5} / \mathrm{m}\right)$, was measured in the sample to which $15 \%$ GDC was added.

As shown in Fig. 5 (a) and (b), the change in the coefficient of friction for all composites under both loading conditions is maintained within a narrow range of 0.1 or less, indicating that the coefficient of friction was not affected by the amount of GDC added. With a given constant roughness as a surface treatment prior to the experiment, the average coefficient of friction in the steady state of the specimen tends to change with the applied vertical load rather than the positive effect of the added GDC. Wang et al. [35] showed that the coefficient of friction is a system value that is only affected by the various contact interfaces under shear stress and that it is a variable parameter that can be adjusted by removing individual asperities. This is consistent with the results in Fig. 5; it is evident that there is no direct relationship between the wear and the coefficient of friction of the composite according to the composition ratio. Wang et al. [36] investigated the effects of wear particles on the tangential acceleration in the stickslip oscillation environment of five different materials under the same external conditions. It was found that the wear particle called the third body, generated during the friction process, acts as a lubricant at the contact interface, reducing the stick-slip vibration that causes tangential acceleration. In addition, Lu et al. [37] reported that the friction-induced vibration and noise generated during the reciprocating motion were caused by stick-slip; through experiments, they showed that the generated tangential acceleration was proportional to the occurrence of wear. Candan et al. [38] classified SiC particle sizes into two types; by adding the same volume fraction to $\mathrm{Al}_{2} \mathrm{O}_{3}$, they observed that the abrasion rate was low in specimens to which small-sized particles were added. Similarly, Kumar et al. [39, 40] observed that grain size reduction through the addition of $\mathrm{TiB}_{2}$ to $\mathrm{Al}$ alloy increased the density of the specimen and suppressed the occurrence of wear. As the wt.\% of the added GDC increased, the 
coefficient of friction did not undergo a dramatic change (Fig. 4(a)); however, it did exhibit a tendency to suppress the occurrence of wear (Fig. 4(d)). This can be attributed to a decrease in the friction-induced vibration acceleration (Fig. 4(c)). NiO, the dominant material, also forms oxides on the contact interface during the friction process and acts as a solid lubricant to protect the base material from severe wear; the generated wear particles also play the role of the third body in protecting the material from wear due to stick-slip (additional details are described in Figs. 6 and 7). In addition, the increase in dislocation density in the material owing to the addition of GDC affords a dense grain structure, which results in a synergistic effect with an increase in the hardness of the composite, thereby suppressing the occurrence of wear.
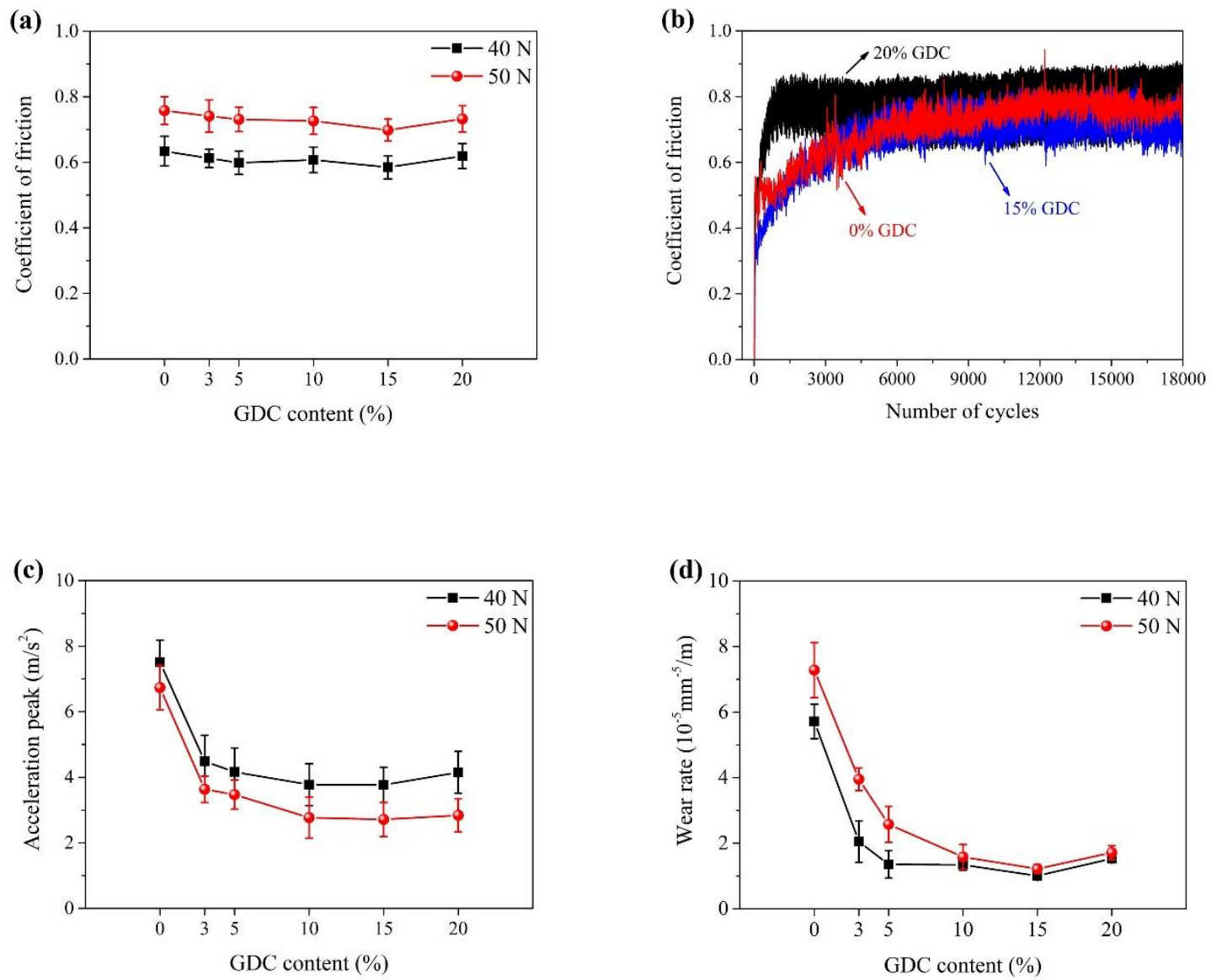

Fig. 5 (a) Average friction coefficient, (b) Friction coefficient of specimens under 50 N, (c) acceleration peak and $(\mathrm{d})$ wear rate of $\mathrm{NiO} / \mathrm{GDC} \mathrm{MMC}$ with different $\mathrm{NiO}$ :GDC mass ratios

Figs. 6 and 7 present microscopic images of the wear spots, 2D profile images, and EDS analysis results. As shown in Fig. 6, as the amount of the added GDC increased, the wear width and depth decreased; this result is consistent with the wear rate trend in Fig. 5(c). Except for pure $\mathrm{NiO}$, when the amount of GDC added increased from $3 \%$ to $20 \%$, the width and depth of the wear spot decreased gradually. Under a normal load of $50 \mathrm{~N}$, as compared to pure $\mathrm{NiO}$, the wear rates of the composites with $15 \%$ and $20 \%$, decreased by $83.27 \%$ and $76.49 \%$, respectively. Regardless of the amount of GDC added, detachment due to adhesive wear was observed during friction in all the composites, and it was more significant in composites with 
less than $10 \%$ GDC. For specimens with more than $10 \%$ GDC, the composite surface featured pronounced plowing, and the $2 \mathrm{D}$ profile indicated the presence of abrasive wear, including pits, owing to the enhancement in hardness. The furrows on the worn surface of the composite were formed due to the plowing, scratching, and micro-scratching by the third body particle acting as an abrasive at the contact interface. However, despite of the occurrence of plowing, the increase in hardness and the reduction in adhesive wear owing to grain refinement reduced the total amount of wear. Therefore, it was concluded that the GDC-added specimens showed better anti-friction and wear performances than pure NiO. Based on the EDS results, shown in Fig. 7, Fe and $\mathrm{O}$ elements were found in the wear scar, indicating that material was transferred from the ball specimen to the pellet through the friction process. In particular, relatively high contents of $\mathrm{Fe}$ and $\mathrm{O}$ elements were detected in the composite with $10 \%$ or more of GDC added. The third body particle acts as a solid lubricant at the contact interface, reducing the stick-slip phenomenon that occurs during friction and suppressing tangential acceleration. Consequently, it protects the substrate from severe wear. According to the observation results in Fig. 6 and 7, adhesive wear and oxidative wear were the primary wear mechanisms.
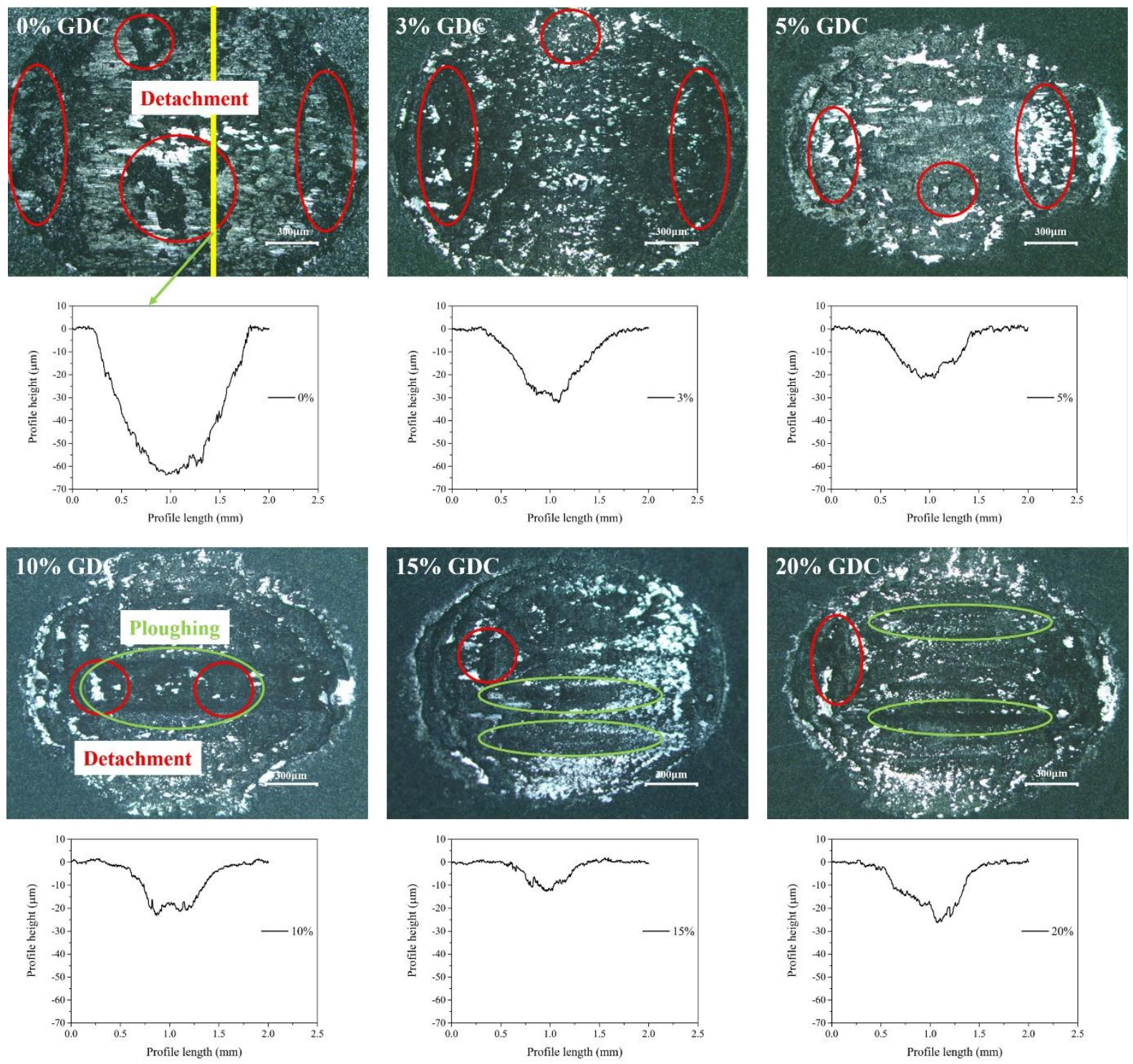

Fig. 6 The optical images and 2-D profiles of the wear tracks of NiO/GDC composites 

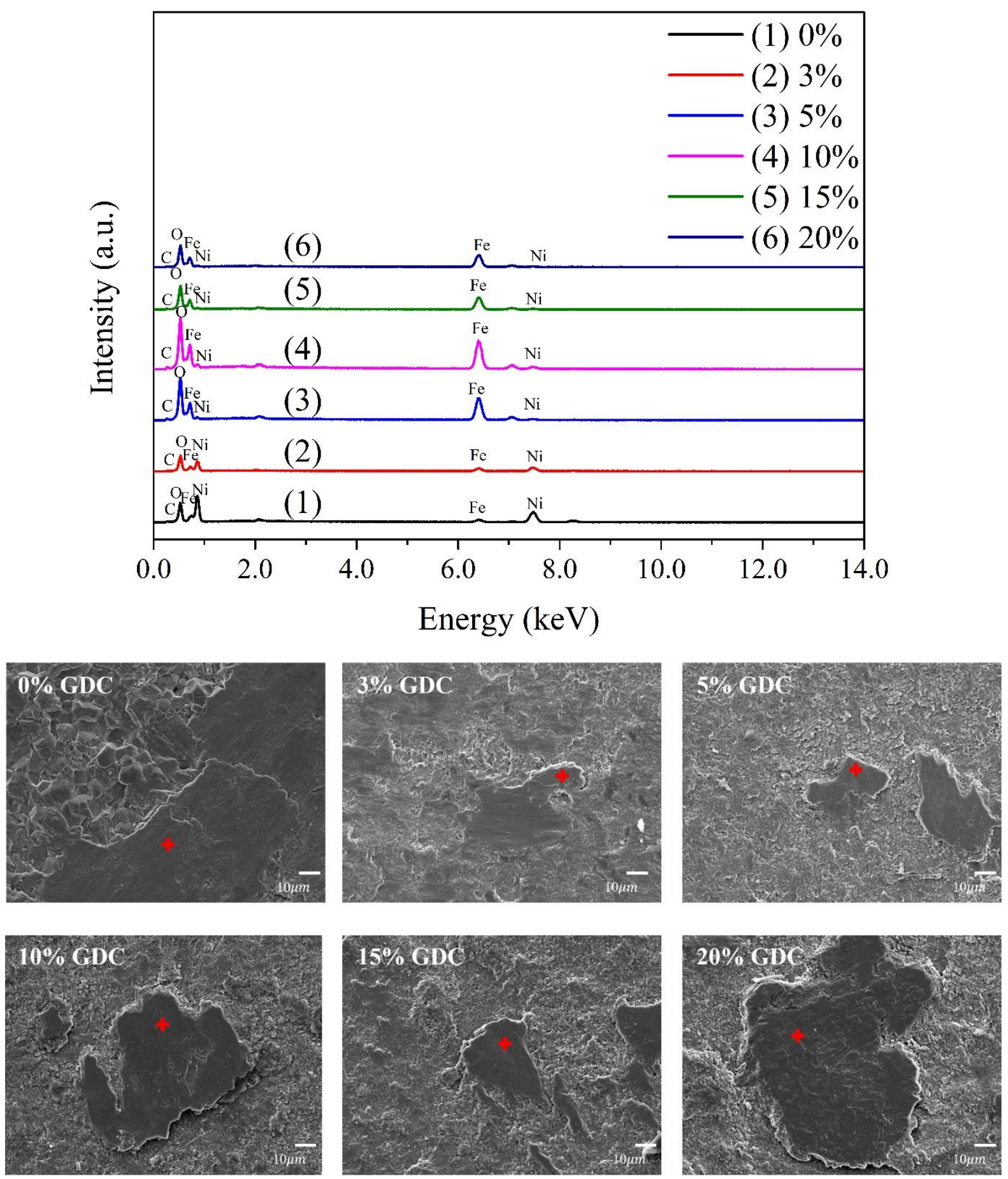

Fig. 7 The SEM/EDS analysis of wear corresponding to NiO/GDC composites

\section{Conclusions}

This paper study investigated the enhanced tribological properties of NiO-based nanocomposites with the addition of GDC. By varying the ratio of GDC added to the composite, at the wear test of the $\mathrm{NiO} / \mathrm{GDC}$ composites was conducted to measure their friction 
characteristics and surface morphologies. Based on the experimental results, the following conclusions can be drawn:

(1) The composite was produced by adding GDC powder to NiO powder as a reinforcement material, and verification of the specimen was performed through XRD analysis. NiO was added instead of $\mathrm{Ni}$ to minimize the generation of impurities such as $\mathrm{Ni}_{2} \mathrm{O}_{3}$, which may be generated during the friction process. As the amount of added GDC increased, the dislocation density in the specimen increased, resulting in the accumulation of misorientation. Consequently, the grain size and hardness increased owing to the increase in dislocation density in the composite.

(2) The acceleration generated by the stick-slip phenomenon during reciprocating frictional movement decreased in magnitude as the amount of added GDC increased. This was owing to the suppression of the stick-slip phenomenon at the contact interface by the wear particles generated during friction, which acted as third body particles. As a result, the addition of GDC reduced the grain size of the composite, increased the hardness, and improved the tribological properties through the synergetic effect of the solid lubricating action of $\mathrm{NiO}$ and the wear particles acting as the third body.

\section{Acknowledgements}

This work was supported by the he National Research Foundation of Korea (NRF) funded by the Ministry of Science, ICT \& Future Planning (Grant No.2019R1A2C4070158). 


\section{References}

[1] Sheikh-Ahmad, J. and J. Davim, Tool wear in machining processes for composites, in Machining technology for composite materials. 2012, Elsevier. p. 116-153.

[2] Ibrahim, I., F. Mohamed, and E. Lavernia, Particulate reinforced metal matrix composites - a review. Journal of materials science, 1991. 26(5): p. 1137-1156.

[3] Aruna, S., et al., Synthesis and properties of electrodeposited Ni/ceria nanocomposite coatings. Surface and Coatings Technology, 2006. 200(24): p. 6871-6880.

[4] Hovestad, A. and L. Janssen, Electrochemical codeposition of inert particles in a metallic matrix. Journal of Applied Electrochemistry, 1995. 25(6): p. 519-527.

[5] Clauss, F.J., Solid lubricants and self-lubricating solids. 2012: Elsevier.

[6] Scharf, T. and S. Prasad, Solid lubricants: a review. Journal of materials science, 2013. 48(2): p. 511-531.

[7] Flores, J., et al., An experimental study of the erosion-corrosion behavior of plasma transferred arc MMCs. Wear, 2009. 267(1-4): p. 213-222.

[8] Rahman, M.S., et al., Tribology of incoloy 800 HT for nuclear reactors under helium environment at elevated temperatures. Wear, 2019. 436: p. 203022.

[9] Aruna, S., V.W. Grips, and K. Rajam, Ni-based electrodeposited composite coating exhibiting improved microhardness, corrosion and wear resistance properties. Journal of Alloys and compounds, 2009. 468(1-2): p. 546-552.

[10] Shu, D., et al., In situ synthesized high volume fraction WC reinforced Ni-based coating by laser cladding. Materials Letters, 2017. 195: p. 178-181.

[11] Xuelong, P., et al., Effect of $\mathrm{Nb}$ addition on microstructure and properties of laser cladding NiCrBSi coatings. Transactions of the IMF, 2018. 96(6): p. 304-312.

[12] Stott, F. and G. Wood, The influence of oxides on the friction and wear of alloys. Tribology International, 1978. 11(4): p. 211-218.

[13] Hager Jr, C., et al., The mechanisms of gross slip fretting wear on nickel oxide/Ti6Al4V mated surfaces. Wear, 2010. 268(9-10): p. 1195-1204.

[14] Masouros, G., A. Dimarogonas, and K. Lefas, A model for wear and surface roughness transients during the running-in of bearings. Wear, 1977. 45(3): p. 375382.

[15] Chen, L., et al., Running-in process of Si-SiO x/SiO 2 pair at nanoscale-Sharp drops in friction and wear rate during initial cycles. Friction, 2013. 1(1): p. 81-91.

[16] Chi, H., et al., The tribological behavior evolution of TiB2/Al composites from running-in stage to steady stage. Wear, 2016. 368: p. 304-313.

[17] Marian, M., et al., MXene nanosheets as an emerging solid lubricant for machine elements-Towards increased energy efficiency and service life. Applied Surface Science, 2020: p. 146503.

[18] Pattnaik, A.B. and S. Das, Probability of Formation of Wear Debris during Initial Running-In Period of Sliding Wear of Al-Si (LM13)-10 wt.\% Fly Ash Composites. Journal of Materials Engineering and Performance, 2020. 29(11): p. 7480-7487.

[19] Nwanya, A.C., et al., Zea mays lea silk extract mediated synthesis of nickel oxide nanoparticles as positive electrode material for asymmetric supercabattery. Journal of Alloys and Compounds, 2020. 822: p. 153581.

[20] Tromans, D. and J. Meech, Fracture toughness and surface energies of minerals: theoretical estimates for oxides, sulphides, silicates and halides. Minerals Engineering, 2002. 15(12): p. 1027-1041.

[21] Phuong, D.D., et al., Influence of sintering temperature on microstructure and mechanical properties of WC-8Ni cemented carbide produced by vacuum sintering. 
Ceramics International, 2016. 42(13): p. 14937-14943.

[22] Morales, M., et al., Mechanical properties at the nanometer scale of GDC and YSZ used as electrolytes for solid oxide fuel cells. Acta materialia, 2010. 58(7): p. 25042509.

[23] Muthukkumaran, K., et al., Thermal properties of 15-mol\% gadolinia doped ceria thin films prepared by pulsed laser ablation. Ionics, 2007. 13(1): p. 47-50.

[24] Lee, Y.H., et al., Platinum-based nanocomposite electrodes for low-temperature solid oxide fuel cells with extended lifetime. Journal of Power Sources, 2016. 307: p. 289296.

[25] Oliver, W.C. and G.M. Pharr, An improved technique for determining hardness and elastic modulus using load and displacement sensing indentation experiments. Journal of materials research, 1992. 7(6): p. 1564-1583.

[26] Anstis, G., et al., A critical evaluation of indentation techniques for measuring fracture toughness: I, direct crack measurements. Journal of the American Ceramic Society, 1981. 64(9): p. 533-538.

[27] Chavan, A., et al., Effect of variation of $\mathrm{NiO}$ on properties of $\mathrm{NiO} / \mathrm{GDC}$ (gadolinium doped ceria) nano-composites. Ceramics International, 2012. 38(4): p. 3191-3196.

[28] Nafsin, N., et al., Thermodynamics versus kinetics of grain growth control in nanocrystalline zirconia. Acta Materialia, 2017. 136: p. 224-234.

[29] Soares, M.R., et al., Unraveling the Role of Sn Segregation in the Electronic Transport of Polycrystalline Hematite: Raising the Electronic Conductivity by Lowering the Grain-Boundary Blocking Effect. Advanced Electronic Materials, 2019. 5(6): p. 1900065.

[30] Estrin, Y. and A. Vinogradov, Extreme grain refinement by severe plastic deformation: $A$ wealth of challenging science. Acta materialia, 2013. 61(3): p. 782-817.

[31] Zehetbauer, M. and V. Seumer, Cold work hardening in stages IV and V of FCC metals - I. Experiments and interpretation. Acta metallurgica et materialia, 1993. 41(2): p. 577-588.

[32] Pantleon, W. Formation of disorientations in dislocation structures during plastic deformation. in Solid State Phenomena. 2002. Trans Tech Publ.

[33] Hadzima, B., et al. Microstructure and corrosion behaviour of ultrafine-grained copper. in Materials Science Forum. 2006. Trans Tech Publ.

[34] Shi, J. and M. Zikry, Grain size, grain boundary sliding, and grain boundary interaction effects on nanocrystalline behavior. Materials Science and Engineering: A, 2009. 520(1-2): p. 121-133.

[35] Wang, A., et al., Effect of surface roughness on friction-induced noise: exploring the generation of squeal at sliding friction interface. Wear, 2018. 402: p. 80-90.

[36] Wang, X., et al., An investigation of stick-slip oscillation of Mn-Cu damping alloy as a friction material. Tribology International, 2020. 146: p. 106024.

[37] Lu, G., et al., Effects of functionally gradient structure of Ni3Al metal matrix selflubrication composites on friction-induced vibration and noise and wear behaviors. Tribology international, 2019. 135: p. 75-88.

[38] Candan, E., H. Ahlatci, and H. Çïmenoğlu, Abrasive wear behaviour of Al-SiC composites produced by pressure infiltration technique. Wear, 2001. 247(2): p. 133138.

[39] Kumar, S., et al., Tensile and wear behaviour of in situ Al-7Si/TiB2 particulate composites. Wear, 2008. 265(1-2): p. 134-142.

[40] Kala, H., K. Mer, and S. Kumar, A review on mechanical and tribological behaviors of stir cast aluminum matrix composites. Procedia Materials Science, 2014. 6: p. 
1951-1960. 
Figures

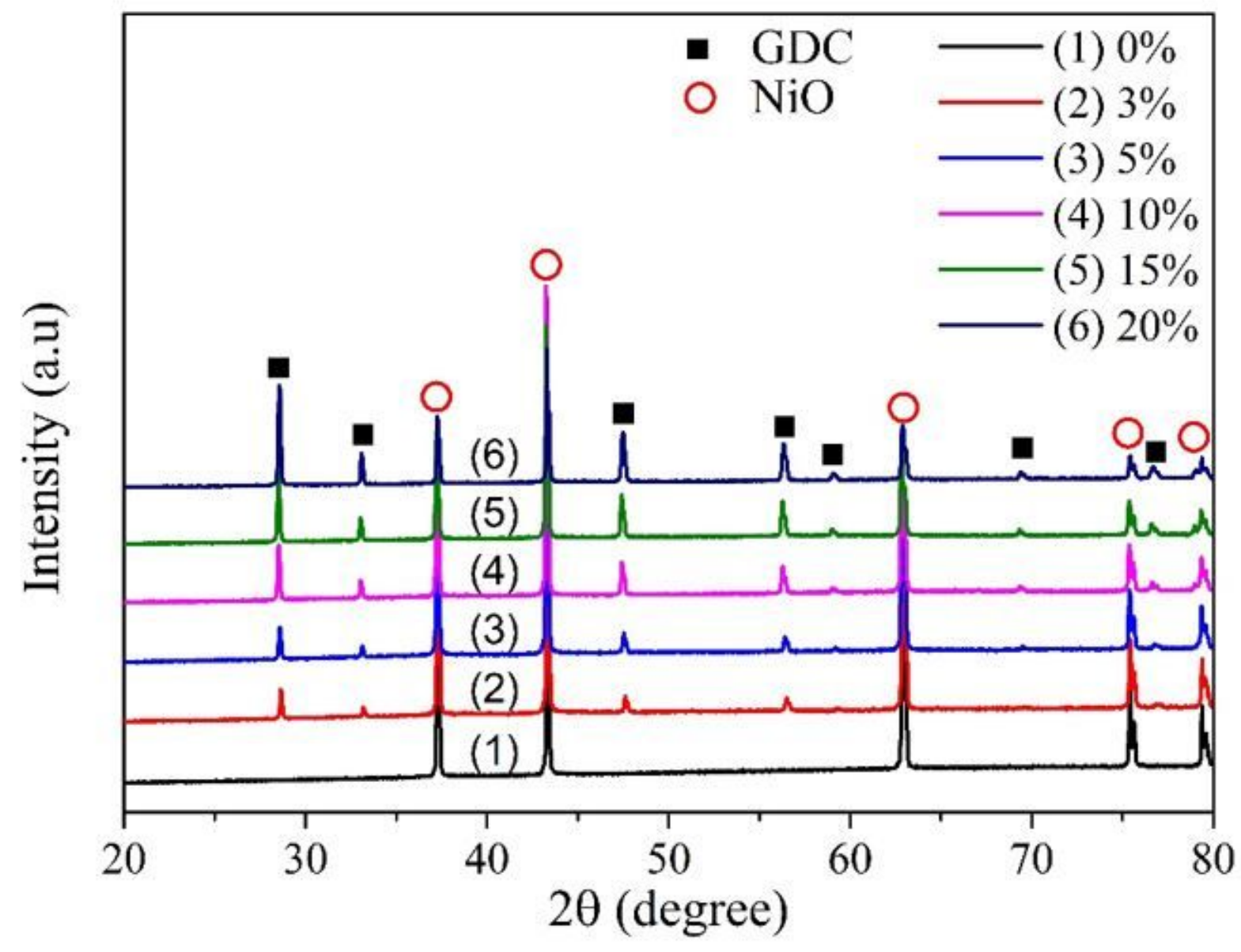

Figure 1

XRD patterns of NiO/GDC composite 

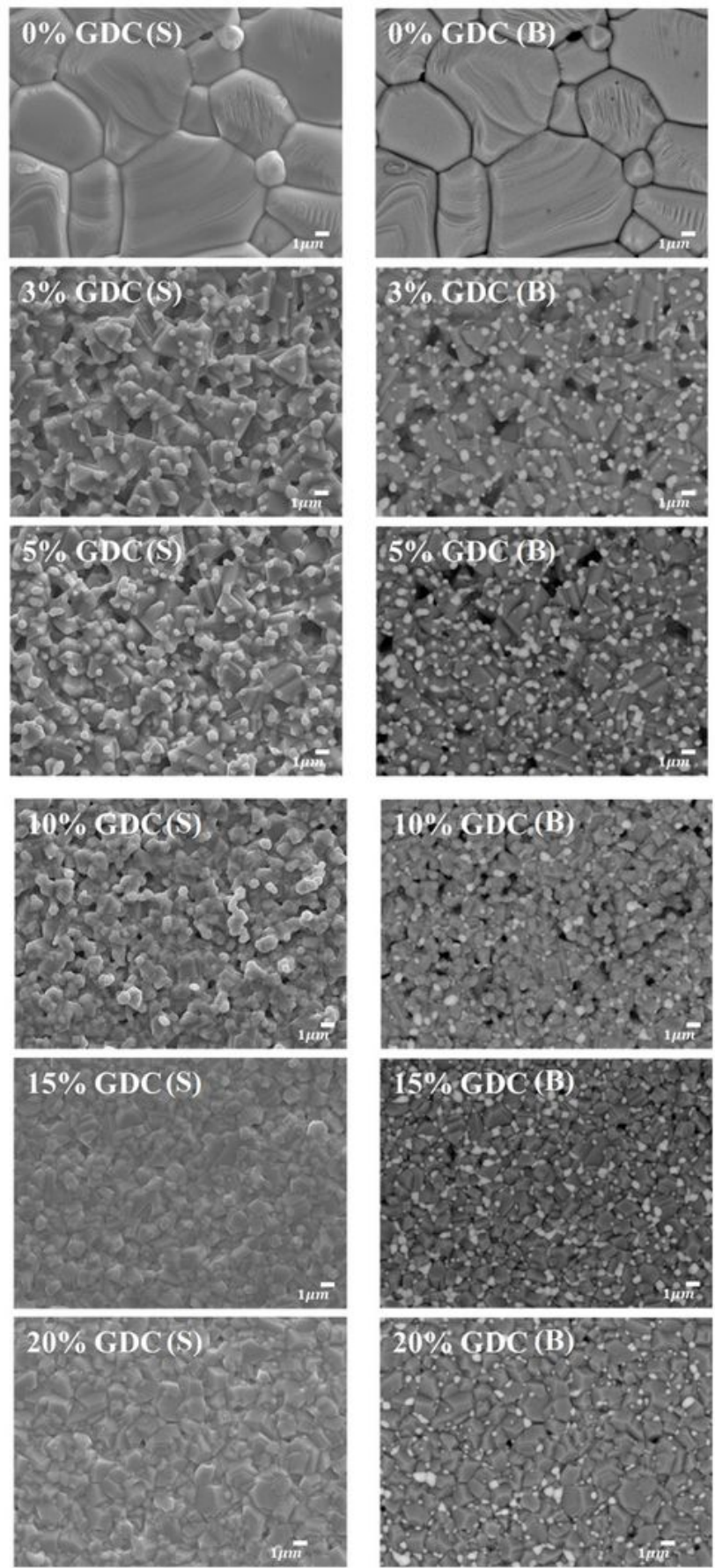

Figure 2

SEM images of samples, S for SEl image (left) and B for BEl image (right). 

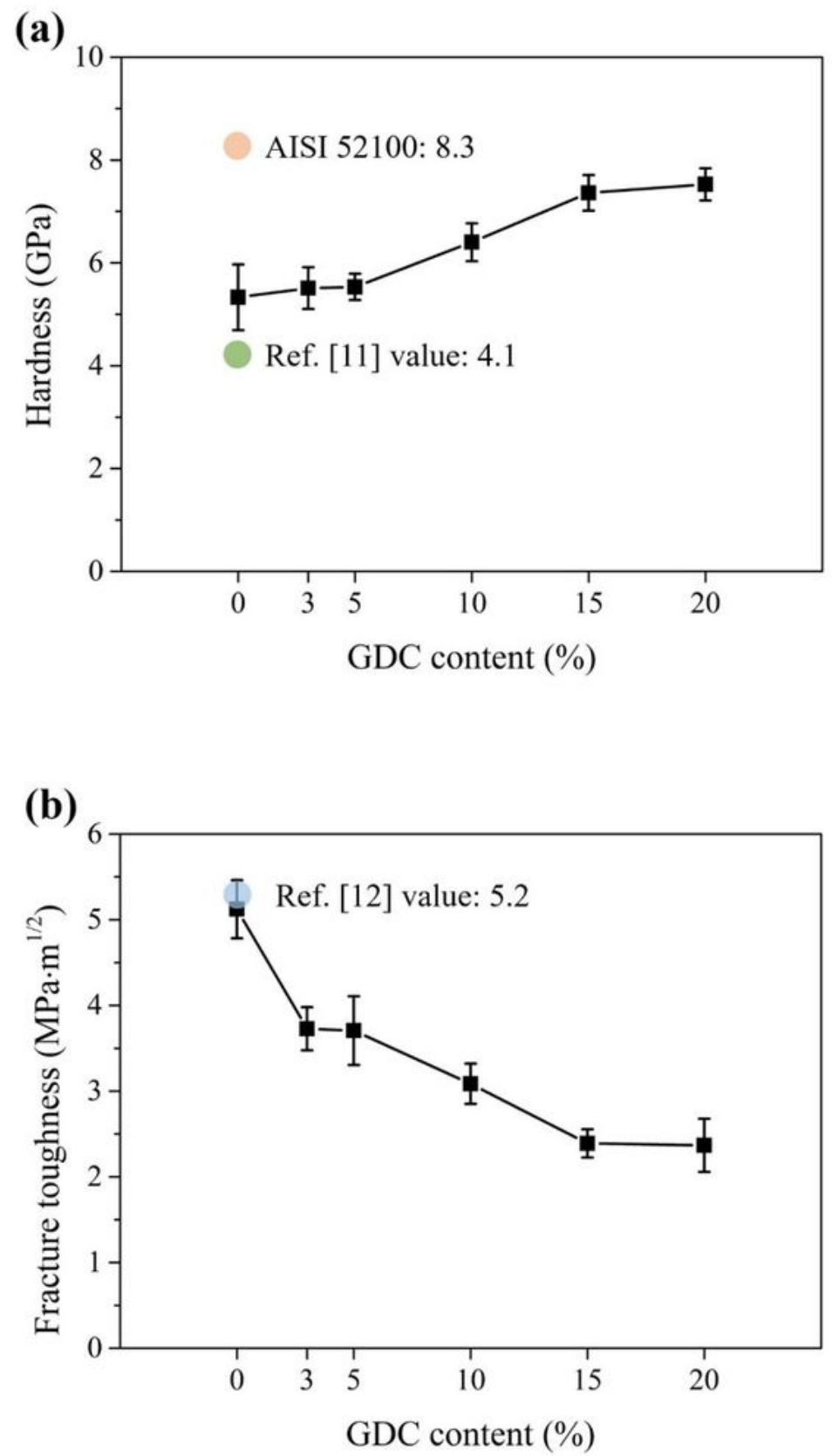

Figure 3

Micro-hardness and fracture toughness of NiO/GDC composites according to the added GDC mass ratio (a) Micro-hardness (Vickers hardness, GPa), (b) Fracture-Toughness(K_IC, MPa $₫ \mathrm{~m}^{\wedge}(1 / 2)$ ). 


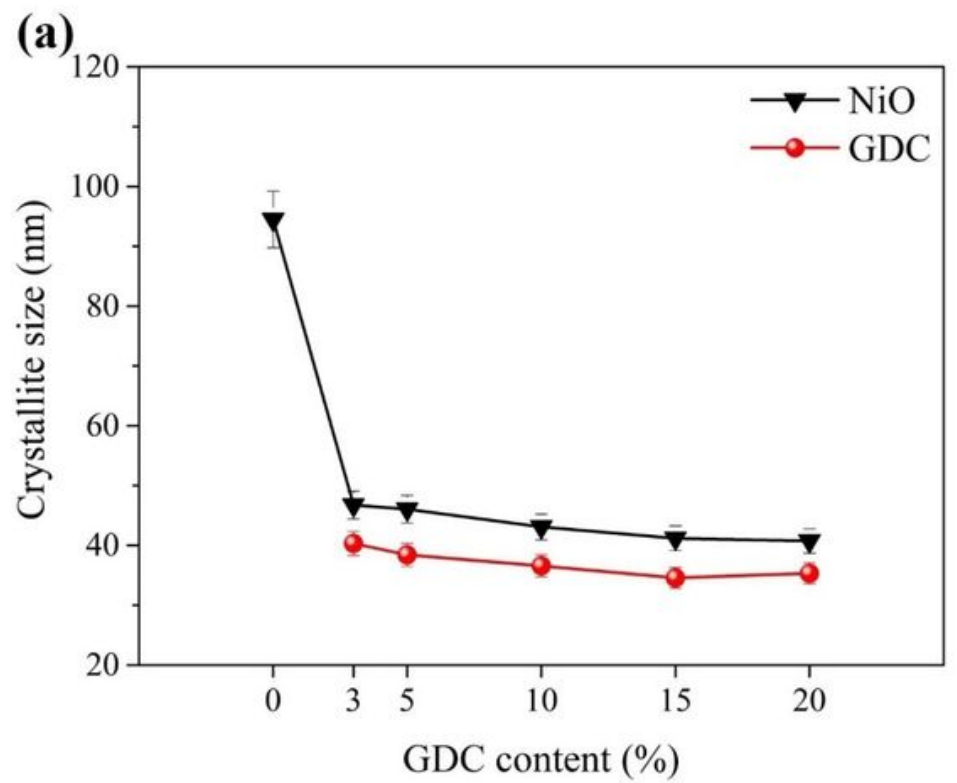

(b)

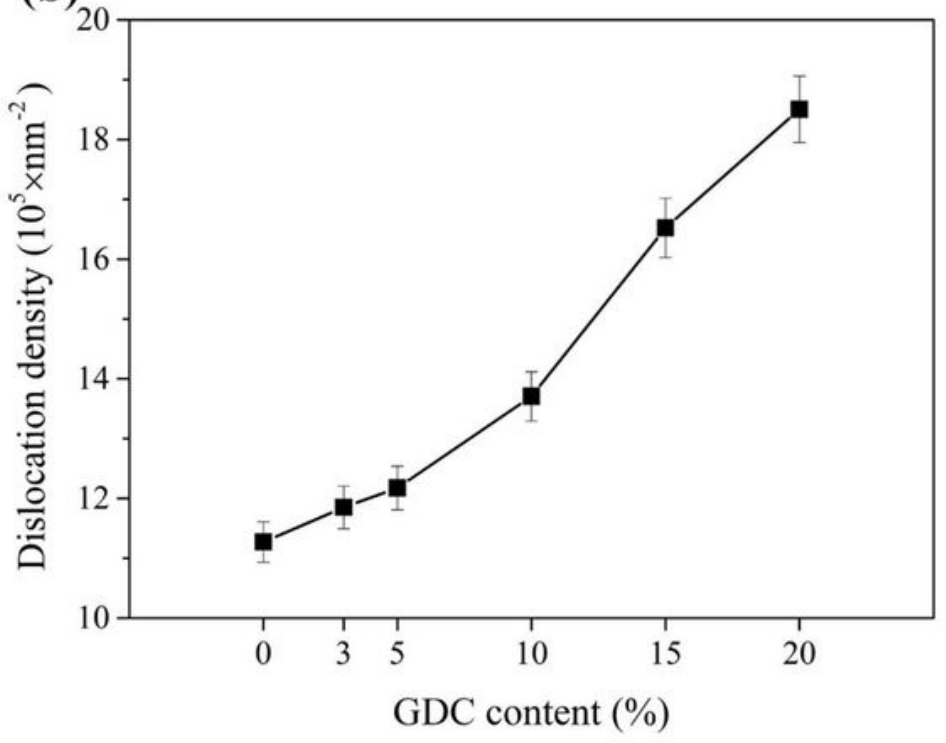

Figure 4

please see the manuscript file for the full caption 

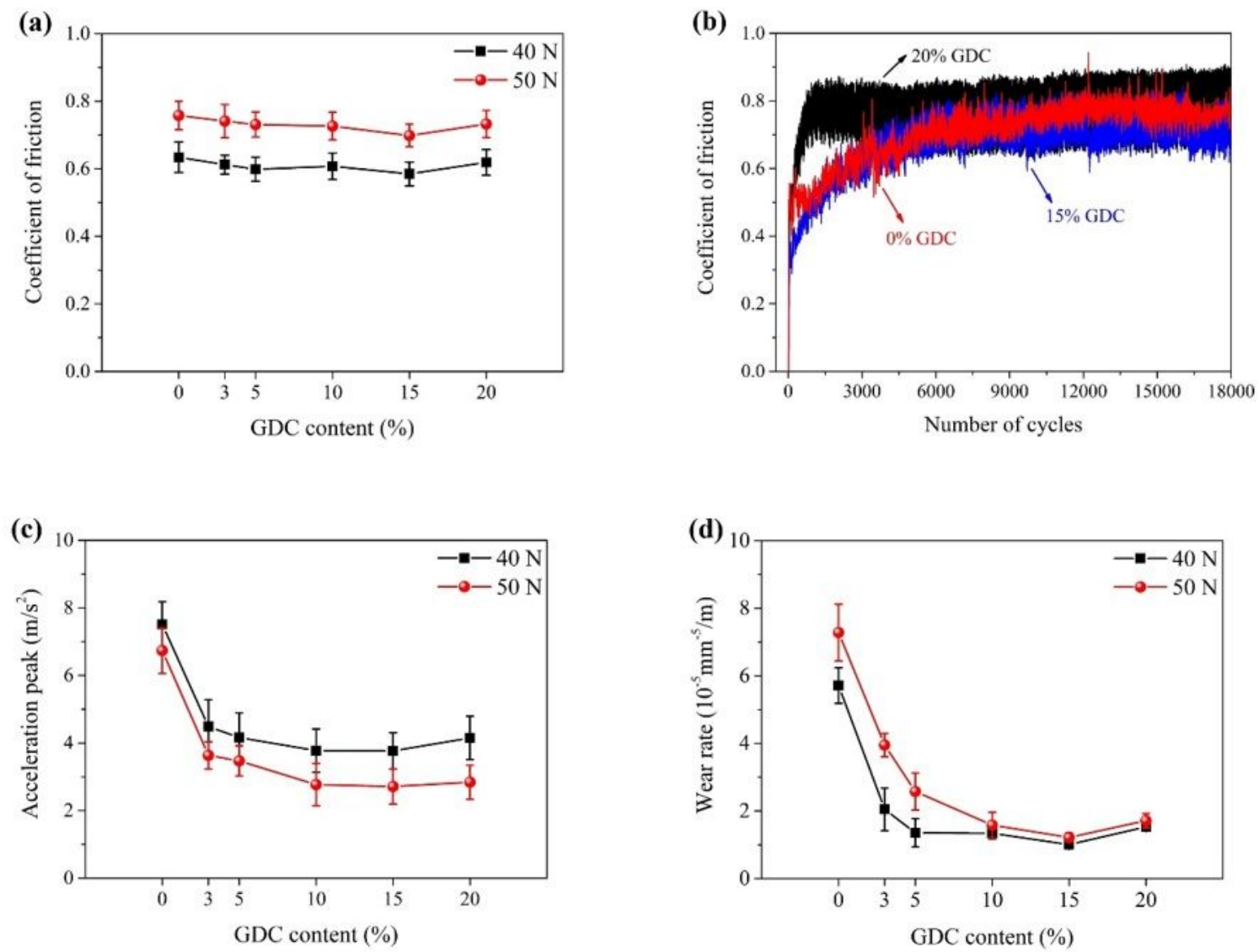

Figure 5

(a) Average friction coefficient, (b) Friction coefficient of specimens under $50 \mathrm{~N}$, (c) acceleration peak and (d) wear rate of $\mathrm{NiO} / \mathrm{GDC} \mathrm{MMC}$ with different $\mathrm{NiO}$ GDC mass ratios 

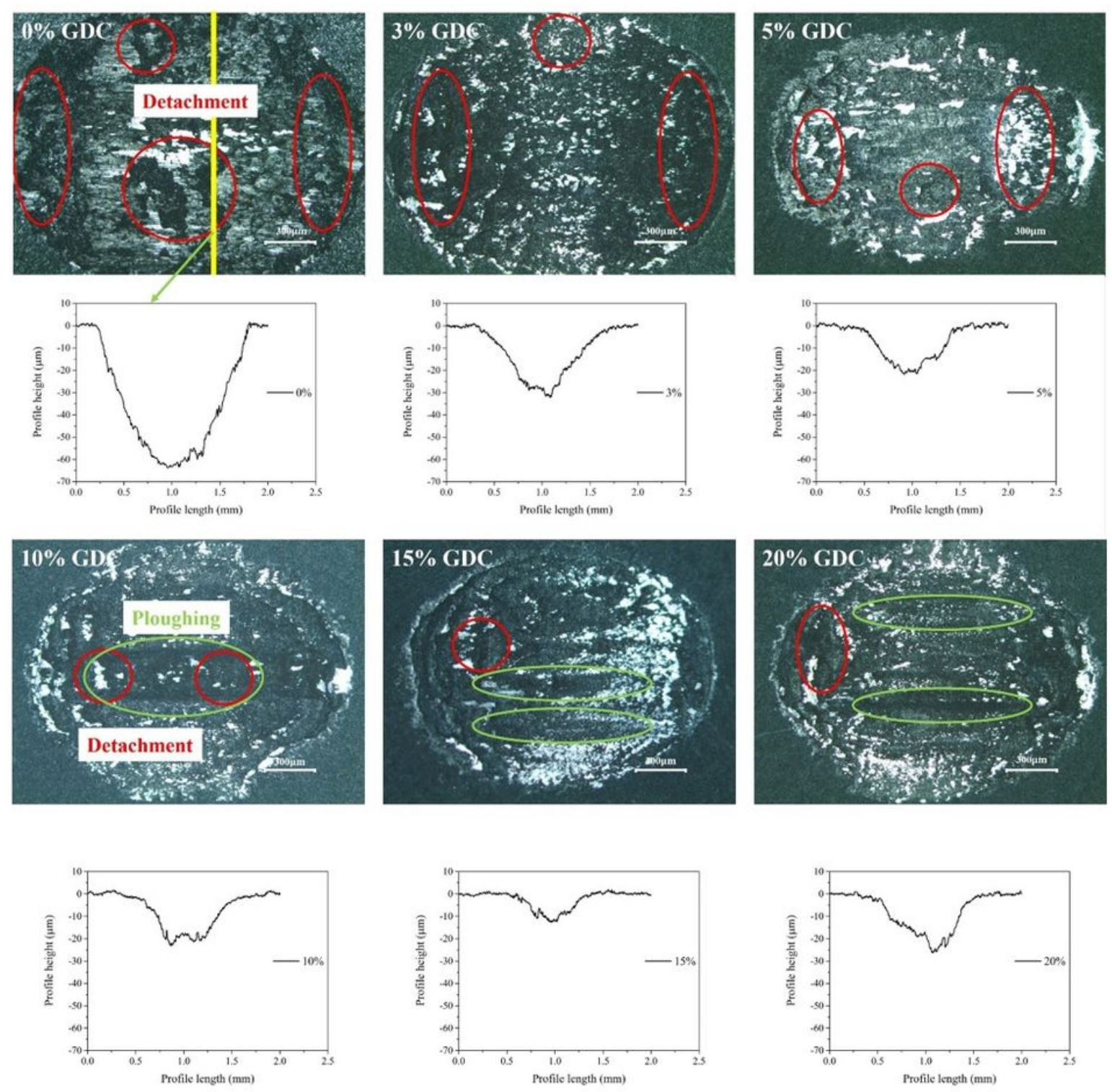

Figure 6

The optical images and 2-D profiles of the wear tracks of NiO/GDC composites 

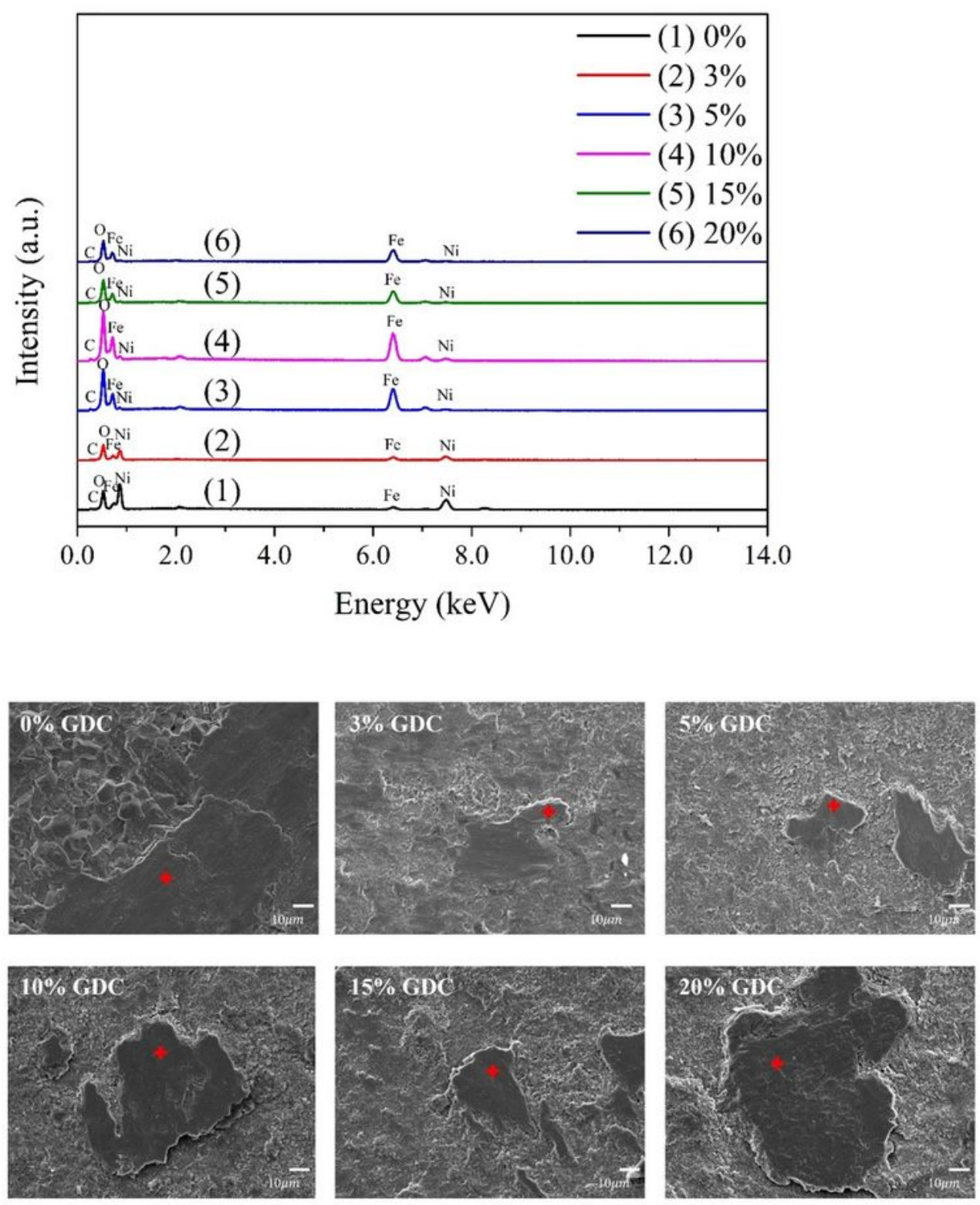

Figure 7

The SEM/EDS analysis of wear corresponding to NiO/GDC composites 